\title{
Tinjauan Karakteristik Tanah Timbunan Sumber Bahan Di Desa Mendalo Darat Kecamatan Jambi Luar Kota
}

\author{
Tommy Tri Setiyanto, Fakhrul Rozi Yamali*, Ari Setiawan \\ Program Studi Teknik Sipil Universitas Batanghari Jambi \\ *Correspondence email: fakhrul_65@yahoo.co.id
}

\begin{abstract}
Abstrak. Pada suatu kawasan atau daerah yang memiliki banyak daerah dataran rendah dan permukaan tanah tidak datar, maka dibutuhkan timbunan agar mendapatkan ketinggian tanah yang direncanakan. Timbunan memerlukan pemadatan tanah agar dapat benar-benar kuat dan stabil terhadap beban struktur maupun beban non struktur.Pada pekerjaan timbunan tanah untuk konstruksi, tanggul, waduk dan konstruksi sipil lainnya, tanah yang belum padat atau masih kondisi gembur harus dipadatkan untuk meningkatkan berat volumenya. Pemadatan tersebut berfungsi untuk meningkatkan kekuatan tanah, sehingga dengan demikian meningkatkan daya dukung pondasi di atasnya. Pemadatan juga dapat mengurangi besarnya penurunan tanah yang tidak diinginkan. Lokasi quarry yang terletak di Jalan Lintas Sumatera tepatnya di desa Mendalo darat Kecamatan Jambi Luar Kota, lokasi Quarry tersebut mempunyai luas $\pm 16 \mathrm{Ha}$, quarry telah beroperasi selama \pm 7 bulan , lokasi quarry tersebut mempunyai beberapa fungsi tanah diantaranya tanah timbunan jalan dan tanah timbunan bangunan.Penelitian ini dilakukan untuk mengetahui karakteristik tanah timbunan yang berlokasi di desa mendalo darat kecamatan jambi luar kota, dimana di lokasi tersebut terdapat suatu quarry yang mana quarry tersebut belum mengetahui kualitas tanah di quarry tersebut.
\end{abstract}

Kata kunci : Tanah, Klasifikasi Tanah, Kualitas Tanah

\section{PENDAHULUAN}

Tanah dasar (Sub Grade) adalah lapisan tanah paling bawah yang berfungsi sebagai tempat perletakkan lapis perkerasan dan mendukung konstruksi perkerasan jalan diatasnya. Tanah dasar (Sub Grade) dapat berupa tanah asli yang dipadatkan jika tanah aslinya baik, tanah urugan yang didatangkan dari tempat lain atau tanah yang distabilisasikan dengan kapur, semen dan lain lain.

Lokasi quarry yang terletak di Jalan Lintas Sumatera tepatnya di desa Mendalo darat Kecamatan Jambi Luar Kota, lokasi Quarry tersebut mempunyai luas $\pm 16 \mathrm{Ha}$, quarry telah beroperasi selama \pm 7 bulan , lokasi quarry tersebut mempunyai beberapa fungsi tanah diantaranya tanah timbunan jalan dan tanah timbunan bangunan. Berdasarkan uraian diatas, penulis mengambil lokasi quarry tersebut dikarena lokasi tersebut belum ada yang melakukan pengecekan kualitas tanah di quarry tersebut.

\section{Landasan Teori}

Tanah adalah material yang terdiri dari agregat (butiran) mineral-mineral padat yang tidak tersementasi (terikat secara kimia) satu sama lain dari bahan-bahan organik yang telah melapuk (yang berpartikel padat) disertai zat cair juga gas yang mengisi ruang-ruang kosong diantara partikel-partikel padat tersebut (Braja M. Das, 1995). Tanah juga merupakan kumpulan-kumpulan dari bagian-bagian yang padat dan tidak terikat antara satu dengan yang lain (diantaranya mungkin material organik) rongga - rongga diantara material tersebut berisi udara dan air (Verhoef, 1994). Selain itu dalam arti lain tanah merupakan akumulasi partikel mineral atau ikatan antar partikelnya, yang terbentuk karena pelapukan dari batuan (Craig, 1991).

\section{Sistem Klasifikasi AASHTO (The American Association Of State Highway And Transportation Officials) \\ Sistem klasifikasi yang banyak digunakan dalam bidang geoteknik adalah Unified Soil Classification System (USCS) dan system klasifikasi American Association of State Highway and Transportation Officials (AASHTO). Sistem klasifikasi AASHTO dikembangkan dalah tahun 1929 sebagai Public Road Administration Classification System. Sistem ini berguna untuk menentukan kualitas tanah guna perencanaan timbunan jalan, subbase dan subgrade. Pada system ini tanah diklasifikasikan kedalam tujuh kelompok besar yaitu A - 1 sampai dengan A -7 . Tanah yang diklasifikasikan kedalam $\mathrm{A}-1, \mathrm{~A}-2$, dan $\mathrm{A}-3$ adalah tanah berbutir dimana $35 \%$ atau kurang dari jumlah butiran tanah tersebut lolos ayakan No. 200. Tanah lebih dari 35\% butirannya lolos dari ayakan No. 200 kelompok A -4 sampai A - 7 tersebut sebagian besar adalah lanau dan lempung.}

\section{Sistem Unifield Soil Classification System (USCS)}

Metode klasifikasi tanah dengan menggunakan USCS (Unified Soil Classification System) merupakan metode klasifikasi tanah yang cukup banyak digunakan dalam bidang geoteknik. Klasifikasi ini diusulkan oleh A. Cassagrande pada tahun 1942 dan direvisi pada tahun 1952 oleh The Corps of Engeneers and The US Bureau of Reclamation. Pada prinsipnya menurut metode ini, ada 2 pembagian jenis tanah yaitu tanah berbutir kasar (kerikil dan 
Tommy Tri Setiyanto, Fakhrul Rozi Yamali dan Ari Setiawan, Tinjauan Karakteristik Tanah Timbunan Sumber Bahan Di Desa Mendalo Darat Kecamatan Jambi Luar Kota

pasir) dan tanah berbutir halus (lanau dan lempung). Tanah digolongkan dalam butiran kasar jika lebih dari 50\% tertahan di atas saringan no. 200. Sementara itu tanah digolongkan berbutir halus jika lebih dari $50 \%$ lolos dari saringan no. 200.

\section{METODE}

1. Pengujian Analisa Saringan saringan No. 200 (SNI 3423:2008).

2. Pengujian Berat Jenis (SNI1968:2008).

3. Pengujian Batas Atterberg

a. Pengujian Batas Cair (Liquid Limit Test). (SNI1967:2008).

b. Pengujian Batas Plastis (Plastic Limit Test). (SNI1966:2008).

4. Pengujian Pemadatan Tanah (SNI1742:2008).

5. Pengujian CBR (SNI1742:2012).

\section{HASIL DAN PEMBAHASAN}

\section{Perhitungan Analisa Saringan Tanah}

Tabel 1 Analisa Saringan Tanah

\begin{tabular}{cccccc}
\hline \#saringan & $\begin{array}{c}\text { Diameter } \\
\text { butir }(\mathrm{mm})\end{array}$ & $\begin{array}{c}\text { Berat tertahan } \\
(\text { gram })\end{array}$ & $\begin{array}{c}\text { Komulatif tertahan } \\
(\text { gram })\end{array}$ & $\begin{array}{c}\text { Persentase } \\
\text { tertahan }(\%)\end{array}$ & $\begin{array}{c}\text { Persentase } \\
\text { lolos }(\%)\end{array}$ \\
\hline 2 in & 50,4 & 0 & 0 & 0 & 100 \\
1 in & 25,2 & 0 & 0 & 0 & 100 \\
$3 / 8$ in & 9,5 & 26,84 & 26,84 & 3,05 & 96,95 \\
No.4 & 4,75 & 47,38 & 74,22 & 8,43 & 91,57 \\
No.10 & 2 & 52,54 & 126,76 & 14,40 & 85,60 \\
No.40 & 0,425 & 9,75 & 136,52 & 15,51 & 84,49 \\
No.200 & 0,075 & 179 & 315,52 & 35,85 & 64,15 \\
\hline
\end{tabular}

Sumber : Hasil Pengujian Dilaboratorium Teknik Universitas Batanghari 2020.

Tanah yang hilang selama pengujian analisa saringan: $=\frac{\mathrm{W}-\mathrm{W} 1}{\mathrm{~W}} \times 100 \%$

$=\frac{880-315,52}{880} \times 100 \%=0,64 \%<25$ (memenuhi syarat)

\section{Perhitungan Batas - Batas Konsistensi (Atterberg)}

Hasil dari pengujian Atterber Limits dilakukan di Laboratorium berdasarkan SNI 1966 - 2008 dan SNI 1967 2008 dari berat kering tanah dengan pemeraman 1 x 24 jam. Pengujian meliputi bats cair, batas plastis untuk mencari indeks plastisitas, hasil pengujian dapat dilihat pada tabel 2:

Tabel 2 Konsistensi Atterberg.

\begin{tabular}{llcccccc}
\hline \multicolumn{1}{c}{ Uraian } & \multicolumn{3}{c}{ Batas cair (SNI 03-1967) } & \multicolumn{2}{c}{ Batas Plastis } \\
(SNI 03-1966-1990)
\end{tabular}

Sumber : Hasil Pengujian Di Laboratorium Teknik Universitas Batanghari 2020. 


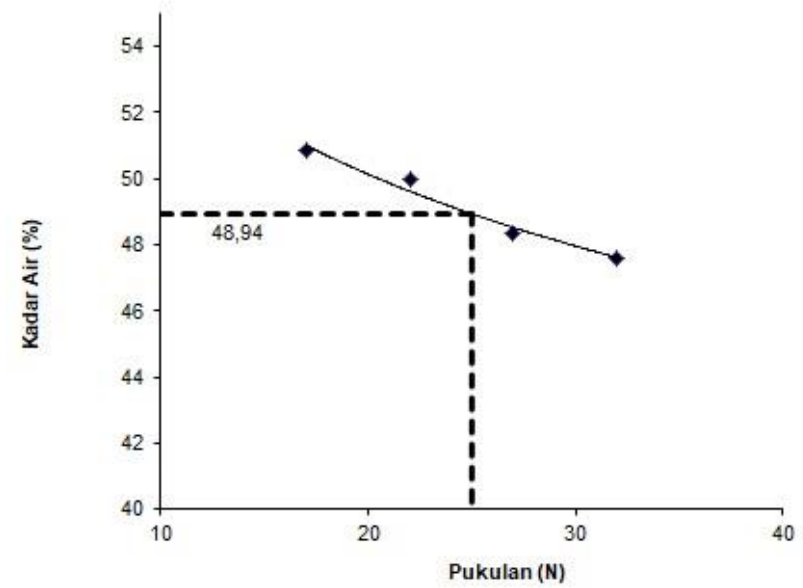

Gambar 1 .Grafik konsistensi atterberg

Sumber : Hasil Pengujian Dilaboratorium Teknik Universitas Batanghari 2020.

Grafik 1 merupakan hubungan antara banyak pukulan dengan kadar airnya. Sehingga dari grafik 1 didapat nilai batas cair pada pukulan ke 25 adalah dengan kadar air sebesar 48,95\%.

Dari hasil pengujian di dapat nilai LL 48,94\% PL 26,44\% dan PI 22,49\%, dapat disimpulkan karena LL kecil dari 50\% dan PL lebih besar dari 7\% dan saringan 200 lebih besar dari 30\% dan batu yang tertahan saringan nomor 4 lebih besar dari 15\% maka menurut pembacaan klasifikasi ASTM tanah dari Quarry di desa Mendalo darat Kecamatan Jambi luar kota termasuk dalam golongan Sandy lean clay.

\section{Perhitungan Pengujian Pemadatan Tanah.}

Tabel 3 Kepadatan Standar Proctor

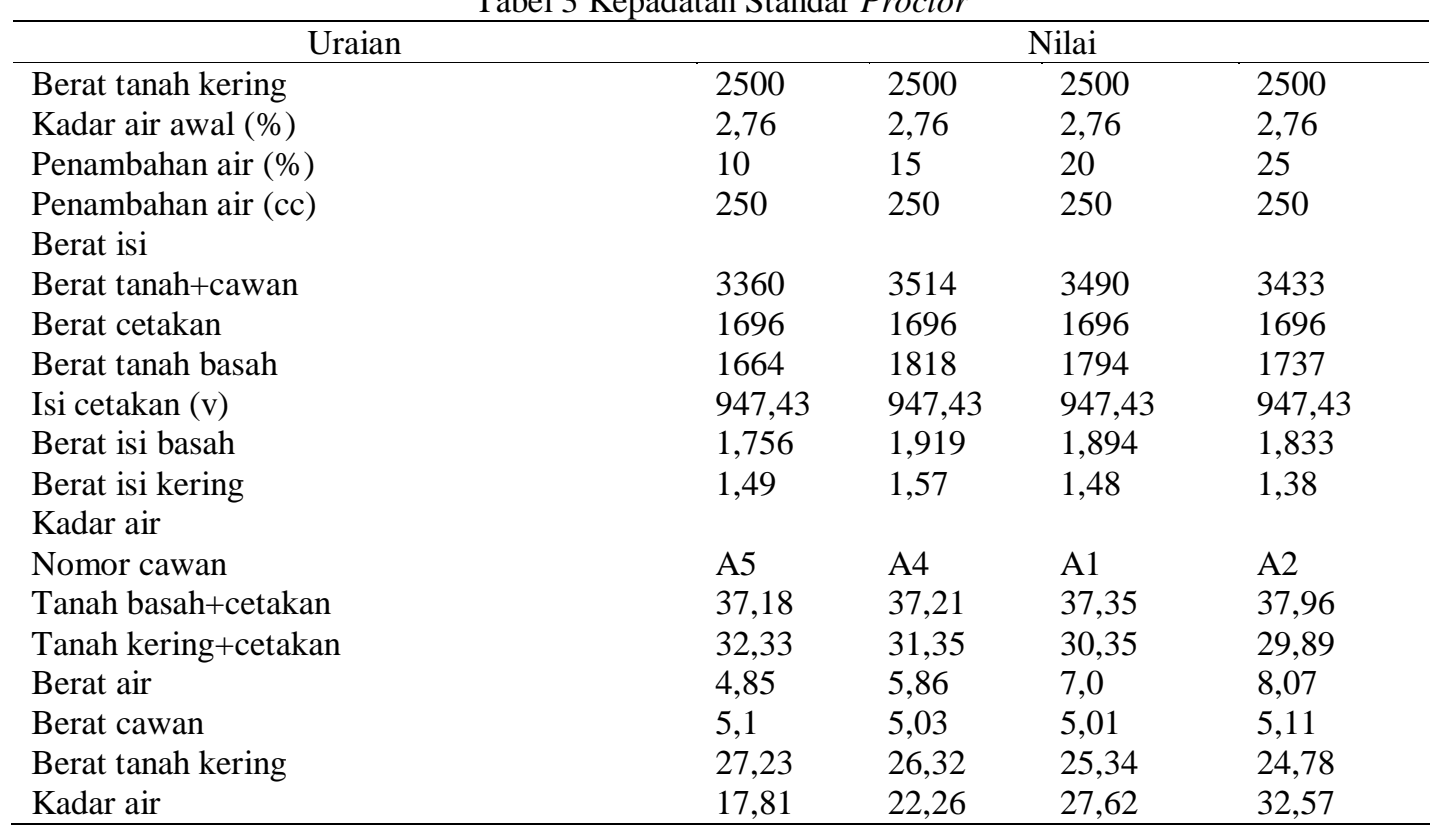

Sumber : Hasil Pengujian Di Laboratorium Teknik Universitas Batanghari 2020

Dari tabel 3 Berat tanah kering awal 2500gram dengan kadar air awal 2,76\% dengan penambahan air 5\% dari setiap pengujian maka di dapat kadar air dari tiap benda uji cawan $\mathrm{A} 5=17,81 \%$, cawan $\mathrm{A} 4=22,26 \%$, cawan $\mathrm{A} 1=27,62$, cawan $\mathrm{A} 2=32,57$. 
Tommy Tri Setiyanto, Fakhrul Rozi Yamali dan Ari Setiawan, Tinjauan Karakteristik Tanah Timbunan Sumber Bahan Di Desa Mendalo Darat Kecamatan Jambi Luar Kota

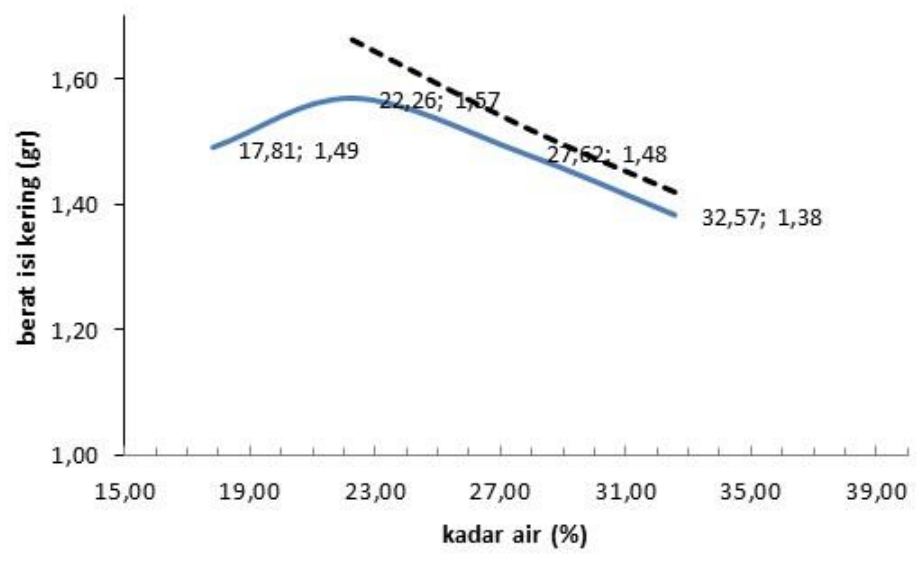

Gambar 2 Grafik Kepadatan Optimum

Sumber : Hasil Pengujian Dilaboratorium Teknik Universitas Batanghari 2020

Dari gambar gerafik 2 kadar air optimum dengan nilai 22,26\%.

Perhitungan CBR Laboratorium (California Bearing Ratio)

Perhitungan CBR (California Bearing Ratio) 3x10 pukulan.

Didapat nilai CBR yang dapat dilihat pada tabel dibawah ini :

Tabel 4 Perhitungan kadar air

\begin{tabular}{lrr}
\hline Kadar air & Sebelum & Sesudah \\
\hline Nomor Cawan & A & A \\
Tanah Basah+Cawan (gram) & 50 & 50 \\
Tanah Kering+Cawan (gram) & 40,55 & 38,58 \\
Air (gram) & 9,45 & 11,42 \\
Berat Cawan (gram) & 5,14 & 5,14 \\
Tanah Kering (gram) & 35,41 & 33,44 \\
Kadar air & 26,69 & 34,15 \\
\hline
\end{tabular}

Sumber : Hasil Pengujian Dilaboratorium Teknik Universitas Batanghari 2020

Dari tabel 4 kadar air sebelum pengujian 26,69\% dan sesudah $34,15 \%$.

Tabel 5 Perhitungan berat isi

\begin{tabular}{lcc}
\hline nomor cetakan : 1 & Sebelum & Sesudah \\
\hline Berat Tanah+Cetakan+Alas & 10,90 & 11,23 \\
Berat Cetakan+Alas & 7,14 & 7,14 \\
Berat Tanah Basah & 3,76 & 4,09 \\
Isi Cetakan & 3215,41 & 3215,41 \\
Berat Isi Basah & 1,17 & 1,27 \\
Berat Isi Kering & 0,92 & 0,95 \\
\hline
\end{tabular}

Sumber : Hasil Pengujian Dilaboratorium Teknik Universitas Batanghari 2020

Dari tabel 5 dapat dilihat hasil dari berat isi basah dan berat isi kering sesudah dan sebelum pengujian, berat isi basah sebelum 1,17 dan sesudah pengujian didapat 1,27 dan berat isi kering sebelum 0,92 dan sesudah pengujian didapat 0,95 .

Perhitungan hasil CBR

$$
\begin{aligned}
& \text { Nilai CBR } \\
& C B R=\frac{\text { Beban } 0,1 \text { in }}{3000} \times 100=\frac{22,36}{3000} \times 100=0,75 \% \\
& C B R=\frac{\text { Beban } 0,2 \text { in }}{4500} X 100=\frac{26,3}{4500} \times 100=0,58 \%
\end{aligned}
$$


Tommy Tri Setiyanto, Fakhrul Rozi Yamali dan Ari Setiawan, Tinjauan Karakteristik Tanah Timbunan Sumber Bahan Di Desa Mendalo Darat Kecamatan Jambi Luar Kota

Dari perhitungan nilai CBR (California Bearing Ratio) dengan jumlah pukulan sebanyak 3x10 pukulan di dapat nilai CBR (California Bearing Ratio) dengan nilai terbesar 0,75\%.

\section{Perhitungan CBR (California Bearing Ratio) 3x25 pukulan.}

Tabel 6 Perhitungan Kadar Air

\begin{tabular}{lcc}
\hline Kadar air & Sebelum & Sesudah \\
\hline Nomor Cawan & B & B \\
Tanah Basah+Cawan & 50 & 50 \\
Tanah Kering+Cawan & 40,22 & 39,47 \\
Air & 9,78 & 10,53 \\
Berat Cawan & 4,90 & 4,90 \\
Tanah Kering & 35,32 & 34,57 \\
Kadar air & 27,69 & 30,46 \\
\hline
\end{tabular}

Sumber : Hasil Pengujian Dilaboratorium Teknik Universitas Batanghari 2020

Dari tabel 6 dapat dilihat kadar air sebelum pengujian dan setelah pengujian didapat kadar air sebelum pengujian $27,69 \%$ dan sesudah $30,46 \%$.

Tabel 7 Perhitungan berat isi

\begin{tabular}{lrr}
\hline nomor cetakan : 2 & Sebelum & \multicolumn{1}{c}{ Sesudah } \\
\hline Berat Tanah+Cetakan+Alas & 11,26 & 11,23 \\
Berat Cetakan+Alas & 7,06 & 7,06 \\
Berat Tanah Basah & 4,20 & 4,36 \\
Isi Cetakan & 3235,11 & 3235,11 \\
Berat Isi Basah & 1,30 & 1,35 \\
Berat Isi Kering & 1,02 & 1,03 \\
\hline
\end{tabular}

Sumber : Hasil Pengujian Dilaboratorium Teknik Universitas Batanghari 2020

Dari tabel 7 dapat dilihat hasil dari berat isi basah dan berat isi kereing sesudah dan sebelum pengujian, berat isi basah sebelum 1,30 dan sesudah pengujian didapat 1,35 dan berat isi kering sebelum 1,02 dan sesudah pengujian didapat 1,03 .

Perhitungan hasil CBR

Nilai CBR

$$
\begin{aligned}
& C B R=\frac{\text { Beban } 0,1 \text { in }}{3000} X 100=\frac{65,75}{3000} X 100=2,19 \% \\
& C B R=\frac{\text { Beban 0,2 in }}{4500} X 100=\frac{105,2}{4500} X 100=2,34 \%
\end{aligned}
$$

Dari perhitungan nilai CBR (California Bearing Ratio) dengan jumlah pukulan sebanyak 3x25 pukulan di dapat nilai CBR (California Bearing Ratio) dengan nilai terbesar 2,34\%.

\section{Perhitungan CBR (California Bearing Ratio) $3 \times 65$ pukulan.}

Tabel 8 Perhitungan Kadar Air.

\begin{tabular}{lcc}
\hline Kadar air & Sebelum & Sesudah \\
\hline Nomor Cawan & $\mathrm{A}$ & $\mathrm{A}$ \\
Tanah Basah+Cawan & 50 & 50 \\
Tanah Kering+Cawan & 40,55 & 40,54 \\
Air & 9,45 & 9,46 \\
Berat Cawan & 5,07 & 5,07 \\
Tanah Kering & 35,48 & 35,47 \\
Kadar air & 26,63 & 26,67 \\
\hline
\end{tabular}

Sumber : Hasil Pengujian Dilaboratorium Teknik Universitas Batanghari 2020

Dari tabel 8 dapat dilihat kadar air sebelum pengujian dan setelah pengujian didapat kadar air sebelum pengujian $26,63 \%$ dan sesudah $26,67 \%$. 
Tommy Tri Setiyanto, Fakhrul Rozi Yamali dan Ari Setiawan, Tinjauan Karakteristik Tanah Timbunan Sumber Bahan Di Desa Mendalo Darat Kecamatan Jambi Luar Kota

Tabel 9 Perhitungan Berat isi.

\begin{tabular}{lcc}
\hline nomor cetakan : 3 & Sebelum & Sesudah \\
\hline Berat Tanah+Cetakan+Alas & 11,43 & 11,58 \\
Berat Cetakan+Alas & 7,02 & 7,02 \\
Berat Tanah Basah & 4,41 & 4,56 \\
Isi Cetakan & 3229,22 & 3229,22 \\
Berat Isi Basah & 1,37 & 1,41 \\
Berat Isi Kering & 1,08 & 1,11 \\
\hline
\end{tabular}

Sumber : Hasil Pengujian Dilaboratorium Teknik Universitas Batanghari 2020

Dari tabel 9 dapat dilihat hasil dari berat isi basah dan berat isi kereing sesudah dan sebelum pengujian, berat isi basah sebelum 1,37 dan sesudah pengujian didapat 1,41 dan berat isi kering sebelum 1,08 dan sesudah pengujian didapat 1,11 .

Perhitungan hasil CBR

$$
\begin{aligned}
& \text { Nilai CBR } \\
& C B R=\frac{\text { Beban } 0,1 \text { in }}{3000} X 100=\frac{118,35}{3000} \times 100=3,59 \% \\
& C B R=\frac{\text { Beban } 0,2 \text { in }}{4500} X 100=\frac{177,53}{4500} \times 100=3,94 \%
\end{aligned}
$$

Dari perhitungan CBR (California Bearing Ratio) dengan jumlah pukulan sebanyak 3x65 pukulan di dapat nilai CBR (California Bearing Ratio) dengan nilai terbesar 3,95\%.

Tabel 10 Hasil Perhitungan CBR (California Bearing Ratio) Desain pada kadar air optimum

Hasil Pengujian CBR

\begin{tabular}{llcc}
\hline Jumlah Tumbukan/Lapis & 3 X10 & 3 X25 & 3 X65 \\
\hline CBR & 0,75 & 2,34 & 3,95 \\
Densitas kering & 0,95 & 1,03 & 1,11 \\
\hline & & & SNI 1742:2008 \\
\hline Cara Pemadatan & & 22,26 \\
\hline Kadar Air Optimum & $(\%)$ & 1,11 \\
Densitas Kering Maksimum (yd maks) & g/cm3) & 1,055 \\
Densitas Kering Desain (95\% yd maks) & (g/cm3) & 2,75 \\
CBR Desain & 95\% MDD & 3,95 \\
& 100\% MDD & \\
\hline
\end{tabular}

Sumber : Hasil Pengujian Dilaboratorium Teknik Universitas Batanghari 2020.

Dari tabel 10 penentuan CBR (California Bearing Ratio) desain pada kadar air optimum dapat dilihat kadar air optimum 22,26\%, densitas kering maksimum $1,11 \mathrm{~g} / \mathrm{cm}^{3}$ dan densitas kering maksimum didapat $1,055 \mathrm{~g} / \mathrm{cm}^{3} \mathrm{dan}$ nilai CBR (California Bearing Ratio) desain dengan 95\%MDD (maximum dry density) 2,75\%.

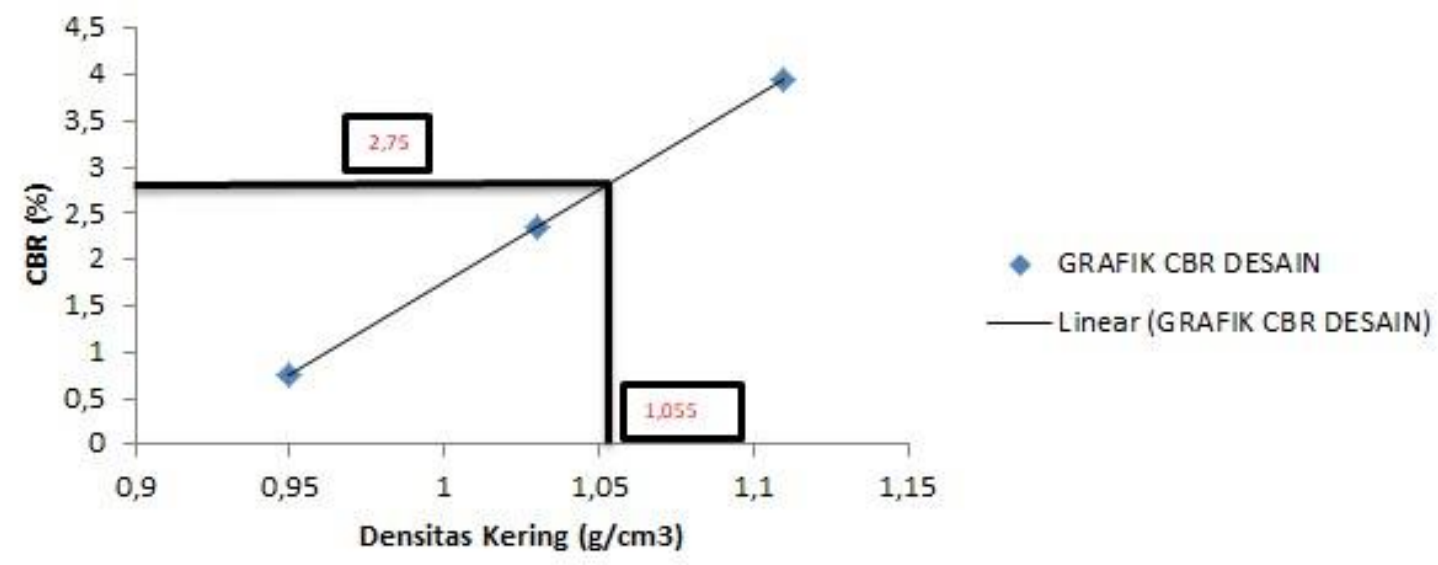


Tommy Tri Setiyanto, Fakhrul Rozi Yamali dan Ari Setiawan, Tinjauan Karakteristik Tanah Timbunan Sumber Bahan Di

\section{Gambar 3 Grafik CBR (California Bearing Ratio) Desain}

Sumber : Hasil Pengujian Dilaboratorium Teknik Universitas Batanghari 2020

Dari gambar grarfik 3 kita dapat mengetahui bahwa hasil perhitungan penentuan CBR (California Bearing Ratio) Desain pada kadar air optimum didapat dengan nilai CBR Desain 2,75\% dengan densitas kering 1,055.

Dilihat dari hasil pengujian CBR Laboratorium pada sampel tanah yang bersumber dari Desa Mendalo Darat Kecamatan Jambi luar kota yang menunjukan nilai CBR dibawah Standar yang ditetapkan SNI sebesar 6\% dapat disimpulkan bahwa tanah bejenis kurang baik sebagai tanah timbunan.

\section{SIMPULAN}

Berdasarkan pengujian yang telah dilakukan dilaboratorium Teknik, Universitas Batanghari Jambi tentang Karakteristik tanah timbunan sumber bahan desa Mendalo darat Kecamatan Jambi luar kota. Maka dapat disimpulkan bahwa:

1. Hasil uji laboratorium terhadap quarry tanah timbunan sumber bahan di desa Mendalo darat Kecamatan Jambi luar kota berdasarkan Sistem klasifikasi Unifield Soil Classification termasuk dalam golongan Lempung Plastis rendah pasiran atau Sendy lean clay.

2. Hasil uji CBR laboratorium terhadap quarry tanah timbunan sumber bahan di desa Mendalo darat Kecamatan Jambi luar kota, nilai CBR yang di dapat adalah:

a. Nilai CBR (California Bearing Ratio) $0,75 \%$.

b. Nilai CBR (California Bearing Ratio) 2,34\%.

c. Nilai CBR (California Bearing Ratio) 3,95\%.

d. Nilai CBR (California Bearing Ratio) Desain pada kadar air optimum didapat dengan nilai CBR Desain 2,75\%.

3. Dikarnakan nilai CBR kecil dari 6\% tanah yang bersumber dari Quarry di desa Mendalo darat bisa digunakan sebagai tanah timbunan dengan syarat penambahan campuran batu kapur.

\section{Saran}

Dengan selesainya penelitian Tugas Akhir ini, maka penulis perlu kiranya memberikan saran sebagai berikut :

1. Diperlukan pemahaman yang komprehensif atas hasil uji tanah yang dilakukan terkait dengan penggunaannya sebagai tanah timbunan.

2. Dari hasil pengujian diketahui nilai CBR adalah 2,75\% yang termasuk katagori "buruk". Untuk mencapai nilai CBR 6\% s/d 10\% dengan kategori "Sedang" perlu dilakukan pencampuran dengan jenis tanah Pasir berlanau atau batu kapur, dengan campuran ini kita dapat menaikan nilai CBR.

\section{DAFTAR PUSTAKA}

Craig, R.F. 1991. Mekanika Tanah. PT. Erlangga. Jakarta.

Das, B. M. 1995. Mekanika Tanah (Prinsip-Prinsip Rekayasa Geoteknis) Jilid I . PT. Erlangga. Jakarta.

Hardiyatmo, H. C. 2002. Mekanika Tanah I (3rd ed). Yogyakarta : Gadjah Mada University Press.

Robianti, E., 2017. "Percobaan Pengujian Pemadatan Tanah Metode Standard Proctor Dengan Alat Uji Tekan

Pemadat Modifikasi". Skripsi. Universitas Lampung. Bandar Lampung.

SNI 1742-2008, Cara uji kepadatan ringan untuk tanah, Jakarta, Badan Standarisasi Nasional

SNI 1744-2012, Metode uji CBR laboratorium, Jakarta, Badan Standarisasi Nasional

SNI 1964-2008, Cara uji berat jenis tanah, Jakarta, Badan Standarisasi Nasional

SNI 1965-2008, Cara uji penentuan kadar air untuk tanah dan batuan di laboratorium, Jakarta, Badan Standarisasi

Nasional

SNI 1966-2008, Cara uji penentuan batas plastis dan indeks plastis tanah, Jakarta, Badan Standarisasi Nasional

SNI 1967-2008, Cara uji penentuan batas cair tanah, Jakarta, Badan Standarisasi Nasional

SNI 3423-2008, Cara uji analisa ukuran butir tanah, Jakarta, Badan Standarisasi Nasional

Terzaghi K dan Peck R.B. 1993. Mekanika Tanah dalam Praktek Rekayasa. Jakarta: Erlangga.

Verhoef, P.N.W. 1994. Geologi Untuk Teknik Sipil. PT. Erlangga. Jakarta.

Yamali,F.R 2016 "analisa energi alat pemadat tanah lempung dilapangan" jurnal Civronlit Universitas Batanghari, $1(1), 33-42$

Wesley, L. D. 1977. Mekanika Tanah (cetakan ke VI). Jakarta : Badan Penerbit Pekerjaan Umum. 